\title{
Catechins Green Tea Clones GMB4 Inhibit Inflammation Process of Atherosclerosis Through Decreasing TNF-A Levels
}

\author{
Ema Susanti* ${ }^{*}$, Febiyanti Suratno ${ }^{2}$ \\ ${ }^{1}$ Pharmacy and Food Analys Academy “Putra Indonesia Malang “, Malang, Indonesia \\ ${ }^{2}$ Pharmacy Academy “ Putra Indonesia Malang “, Malang, Indonesia
}

*Email : rna_far@yahoo.co.id

\begin{abstract}
Catechins Green tea clones GMB4 are potential natural subtances to inhibit inflammation process in atherosclerosis. The purpose of this research to determine activity of Catechins Green tea clones GMB4 to decrease TNF- $\alpha$ levels, as well as to determine optimal dose of Catechins. This research was conducted at the Laboratory of Physiology of the University of Brawijaya. The method used in this research is completely randomized design with five treatments: (1) Mice with standard feed (2) mice with high-fat diet (3) mice with high-fat diet + catechins $3 \mathrm{mg} /$ day (4) mice with a diet high fat + catechin $6 \mathrm{mg} /$ day (5) mice with high-fat diet + catechin $24 \mathrm{mg} /$ day. The treatment was done for 60 days and measured levels of TNF- $\alpha$ at the end of the research. The results showed that Catechins green tea clones GMB4 can inhibit the inflammatory process in atherosclerosis through decreasing levels of TNF- $\alpha$ at doses of $3 \mathrm{mg} /$ day. The conclusion of this research is catechins at a dose of $3 \mathrm{mg} /$ day can inhibit inflammation in atherosclerosis significantly.
\end{abstract}

Keywords : GMB 4 green tea clones, Catechins, inflammation, TNF- $\alpha$

\section{INTRODUCTION}

Cardiovascular disease become one of the biggest causes of death in the world. In 2011, the World Health Organization (WHO) notes that the death rate from cardiovascular disease ranked highest. The number of deaths from cardiovascular disease in Indonesia in 2008 as much as $30 \%$ (1). One of the causes of cardiovascular disease are due to plaque attached to the blood vessels that is often referred to as atherosclerosis. Atherosclerosis is an inflammatory disease of the lining of the artery wall due to high blood cholesterol levels, particularly low-density lipoprotein (LDL). This makes the thickening and hardening of the arteries in the tissues, thus increase the rate of blood flow in the blood vessels that can lead to disorders of the heart as a pain in the chest and also the death of heart muscle cells (2). Atherosclerosis was caused several factors. The risk factors that can lead atherosclerosis which are major and minor risk factor. Major risk factors that can not be modified as age, gender and heredity. Minor risk factors that can be modified such as smoking, dyslipidemia, hypertension, physical activity, obesity and diabetes mellitus. In addition to the major risk factors, while the minor risk factors that favor the occurrence of atherosclerosis such as stress, diet, and also from the consumption of alcohol [2]. At this time, a view to trigger the formation of atherosclerosis was merely a result of the levels of LDL in the blood is too high, began to widen towards the inflammatory process. It can stimulate the release of inflammatory cytokines such as tumor necrosis factor- $\alpha$ (TNF- $\alpha$ ), which can cause further damage (3). The inflammatory mediator TNF- $\alpha$ is the greatest role in the inflammatory process and is used as an indicator of cells undergoing oxidative stress, apoptosis and necrosis. Levels of TNF- $\alpha$ released by inflamed cells will increase. To overcome the problem of inflammation, one of the plants that potentially is catechins of green tea as anti-inflammatory. Class shows that the catechins may inhibit inflammation by suppressing NF-kB pathway indirectly will also inhibit the development of atherosclerosis. Green tea clone GMB 4 has been developed by the Central Research Institute for Tea and Quinine Gambung have much higher levels of catechins. Ratnawatiet al, have done the isolation and purification where in $100 \mathrm{~g}$ of green tea contain $14-16 \%$ of isolates of 
Catechins(5). To prove activity Catechins green tea clone GMB 4 on inhibiting inflammation in atherosclerosis through assay of TNF- $\alpha$ level. Furthurmore, use of catechins green tea clones GMB 4 in the future to prevent inflamation of atherosclerosis.

\section{MATERIALS AND METHODS}

This research is an experimental design was completely randomized. This study aimed to determine the effects of Catechins green tea clones GMB 4 on levels of TNF- $\alpha$. Tested directly TNF- $\alpha$ levels in the blood serum of Wistar rats were given high fat diets. Materials used in this research are Catechins the green tea clones GMB 4, standard feed consisting of a mixture of chicken feed $66.6 \%$ and wheat flour $33.4 \%$ and high fat diet consisted of standard feed added with cholesterol $1.9 \%$, cholic acid $0.1 \%$, and $8.9 \%$ lard. Catechins divided into dose $3 \mathrm{mg}, 6 \mathrm{mg}$, and $24 \mathrm{mg} /$ day. Isolates of catechins that have been prepared are given to group of treatment. Dose adjusted to body weight of rats. Surgery have done at the end of treatment, and measured levels of TNF- $\alpha$ in the blood serum of mice.

\section{Measurements TNFa by ELISA}

ELISA method is as follows, first is to determine the amount used in the microtiter well. For making a standard curve, pipetted $100 \mathrm{~mL}$ assay buffer in the wells (as a blank well), pipetted $100 \mathrm{~mL}$ standard 1-7 into a predetermined well. For sample treatment, pipette $100 \mu 1$ sample treatment and incorporated into the well. Microtiter incubated at $37{ }^{0} \mathrm{C}$ for 2 hours. Each well was washed with $3 \mathrm{x}$ $400 \mathrm{~mL}$ wash buffer. Each well is filled with $100 \mu 1$ of conjugate except in the blank. Microtiter incubated at $37{ }^{0} \mathrm{C}$ for 30 minutes. Each well was washed with $3 \mathrm{x} 400 \mathrm{~mL}$ wash buffer. TMB substrate is pipetted as much as $100 \mathrm{~mL}$ and included in each well, then incubated for 30 minutes at room temperature. Stop solution $(\mathrm{HCl}) 100 \mu 1$ pipetted and added to each well for 5 minutes. Absorbance value was read at OD $492 \mathrm{~nm}(6,7)$.

\section{Statistical Analysis}

Data from measurements TNF $\alpha$ level in each treatment is shown as mean and standard deviation if the data has a normal distribution. But if the data distribution is not normal then was done the transformation of data or use the median and the minimum and maximum size as a measure of dispersion. Data analysis using one-way ANOVA followed by Tukey test to see differences in each treatment. Data analysis was performed with a computerized using SPSS for Windows version 17.

\section{RESULT AND DISCUSSION}

This research was conducted at the Laboratory of Physiology of the Faculty of Medicine, University of Brawijaya In this study used twenty five animals that are divided into 5 groups with a given high-fat diet for 8 weeks and observed its effect on TNF $\alpha$ level. Experimental animals used in this study should be qualified so that the homogeneity of the sample until respect to use for research. Body weight of experimental animals determine on before, during and after treatment. The results of the comparison the average body weight before and after treatment can be seen at Figure 1 .

The levels of TNF- $\alpha$ in experimental animals among the treatments have different average when compared to normal feed diet. Animals treated with high-fat diet had an average of TNF levels higher than other treatments. The result of TNF $\alpha$ levels measurement are shown in Table 1 and Figure 2. 


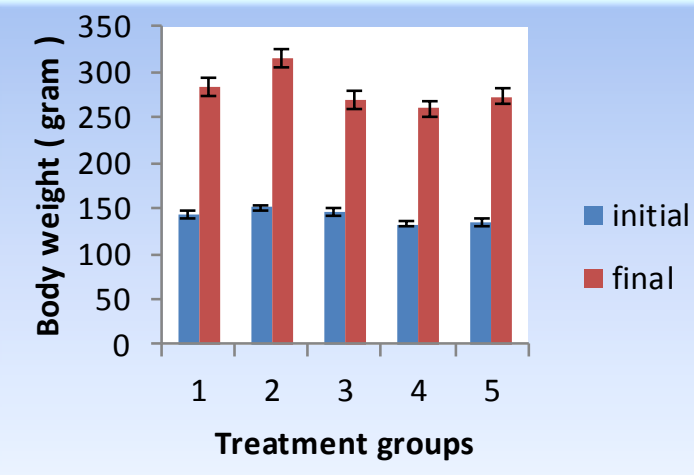

Fig. 1 The comparison the average body weight mice before and after treatment. (1)Negative control ( 2) Positive control (3) Dose I of catechins (4) Dose II of catechins (5) Dose III of catechins

Table 1. TNF $\alpha$ levels in each treatment groups

\begin{tabular}{c|cc}
\hline Groups & Replication & Mean $\pm S D(\mathrm{pg} / \mathrm{ml})$ \\
\hline Control (-) & 4 & $129.000 \pm 37.2648$ \\
Control (+) & 4 & $168.375 \pm 22.4625$ \\
Treatment 1 & 4 & $88.250 \pm 39.2969$ \\
Treatment II & 4 & $114.000 \pm 36.1709$ \\
Treatmen & 4 & $116.875 \pm 30.4997$ \\
& & \\
\hline
\end{tabular}

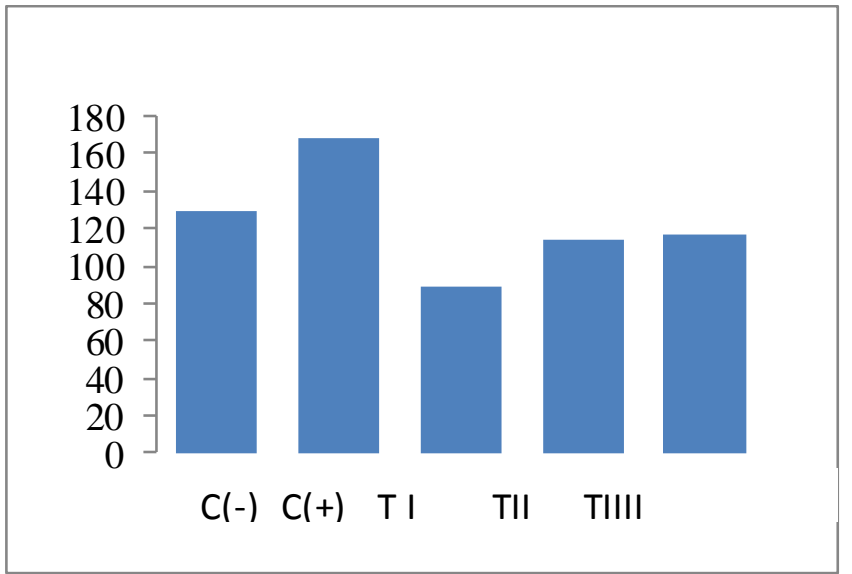

Fig 2. Graphic TNF $\alpha$ levels $(\mathrm{pg} / \mathrm{mL})$ vs groups of treatment 
Test of homegeneity of varience showed significant values for 0685 . Because 0685 is greater than 0.05 , then $\mathrm{H}_{0}$ is accepted. It can be concluded that variants of the same data. To determine whether or not a significant difference in each treatment group, conducted testing using ANOVA.The result Fhitung 3,113 where $F$ tables with significance level $\alpha=0.05$ is 3.055 . It can be seen that there is significant difference in the inhibition of the inflammatory activity in atherosclerosis based on the levels of TNF- $\alpha$ in several animal treatment by administering a dose of $3 \mathrm{mg}$ of catechins.

The experimental animals were treated with high-fat diet for 60 days. The usefulness of the provision of a high-fat diet is to trigger the onset of atherosclerosis. Based on research Ali et al., administration of a high-fat diet can increase blood cholesterol levels and induces the formation of foam cells (8). The addition of cholic acid, cholesterol, and lard aims to raise levels of LDL in the blood. Cholic acid administration aims to increase levels of cholesterol that can form foam cells. The accumulation of oxidized LDL in the vascular wall to be recognized as foreign by the monocytes. Monocytes will turn into macrophages and up take oxidized LDL. The results of the macrophage against oxidized LDL is the formation of foam cells which is an early sign in the process of atherosclerosis (9).

The results showed that administration of catechin can reduce levels of TNF- $\alpha$ in treatment that were given a high-fat diet. Catechins have an important role through covalent bond formed by the cysteine of the protein P60. P60 and P65 protein are subunit of NF-k $\beta$. NF-k $\beta$ is a protein that is responsible for the production of cytokines. With the covalent bonds that can inactivate NF-k $\beta$ so as to reduce the production of cytokines included TNF- $\alpha$. Furthermore, catechins green tea clones GMB 4 is able to inhibit the inflammatory process in atherosclerosis by reduced levels of TNF- $\alpha(10,11)$.

\section{CONCLUSION}

Based on the results of this study can be concluded that Catechins inhibit significantly TNF $\alpha$ levels at dose of $3 \mathrm{mg} /$ day. It can be used as an agent for inhibiting the inflammatory process of atherosclerosis.

\section{ACKNOWLEDGEMENT}

The authors are grateful to Brawijaya University for providing infrastructure for supporting for this research. Thanks for staff at Laboratory of Physiology of the Faculty of Medicine, University of Brawijaya that have given us support and assitance this research.

\section{REFERENCES}

[1] World Health Organization. 2003. Deaths from coronary heart disease, Available from URL :http://www.who.int/cardiovascular_diseases/en/cvd_atlas_14_deathHD.pdf

[2] Yang Z, Ming XF . 2006. Recent Advances in Understanding Endothelial Dysfunction in Atherosclerosis, Clinical Medicine \& Research Review, 53-65.

[3] DeFronzo, R.A. 2010. Insulin Resistance, Lipotoxicity, Type 2 Diabetes and Atherosclerosis : the Missing Link, Diabetologia Reviews

[4] Muniyappa R, Montagnani M, Kon Koh K, Guon, MJ. 2007. Cardiovascular Actions of Insulin, Endocrine Reviews.

[5] Ratnawati, R.; Ciptati; Satuman .2009. Isolation EGCG from green tea GMB4 Clones, West Java. Reports of Incentive Program Basic Research. RISTEK, Ministry of Research and Technology

[6] Aulanni'am. 2003. Principles and techniques of Biomolecular analysis. 78-81

[7] Rantam FA. 2003. Methods Imunology. Airlangga University Press.105-122

[8] Ali M, Muliartha IK. 2004. Optimization of High-Fat Diet in Rats Models Atherogenik, UB Medical Journal: 3 (2): 15-21 
[9] Choo JJ. 2003. Green tea reduces body fat accretion caused by high fat diet in rats trough beta adrenoceptor activation of thermogenesis in brown adipose tissue. J. Nutr. Biochem 14 : 671-676.

[10] Stangl V, Dreger H, Stangl K, ,Moleculer Targets of Tea Polyphenols in the Cardiovascular System, Cardiovascular Research, Oxvord Journal vol 73 issue 2, p. 348-358.

[11] Velayutam P. Babu and Liu. 2008. Green Tea Catechins and Cardiovascular Health ; An Update, Current Medicinal Chemistry, vol 15. No. 18, pp. 1840-1850 